\title{
Commentary
}

\section{A tale of two cities: The influence of literature on medicine}

Christos Tsagkaris ${ }^{1}$, Theodora loannidou ${ }^{2}$

${ }^{1}$ University of Crete, Faculty of Medicine, Heraklion, Greece

${ }^{2}$ University of Thessaly, Faculty of Medicine, Larissa, Greece

Both authors are currently medical students and identify as fiction authors/poets as well

\begin{abstract}
The following piece is a reflection concerning the interplay between the art of writing and the art of medicine. We are exploring the similarities and disparities of the field with a focus on doctors - medical students and fiction authors/poets. We are currently medical students and we identify as poets and fiction authors since our high school years and hence we are trying to point out our perspective. In the end we give some hints about the role that literature can play in modern medicine.
\end{abstract}

Key words: medicine, literature, medical humanities, fiction, poetry

(Heart Vessels Transplant 2021; 5; 44-47; doi: 10.24969/hvt.2020.238)

"For sale: baby shoes, never worn" by E. Hemingway is the shortest piece of fiction in the history of literature. Local news triggered this story, which was most probably written for the sake of a bet (1). Although unintentionally, healthcare issues - namely perinatal mortality - are addressed in this piece. Regardless of the author's intention, the link between medicine and literature dates back to Homer. The connection and discussion in a time, when medical education is shifting towards new paradigms and medical humanities are on the rise (2).

There are many ways in which literature can influence medical practice. First of all, literary accounts of illness can provide physicians with insights regarding the burden of the disease, the attitude of patients and the lives of carers. Moreover, medical - oriented fiction and psychobiography can help physicians ponder ethical dilemmas and controversy. At the same time, a background in humanities can improve the understanding of scientific and diagnostic milestones in medicine and familiarize them with the use of metaphors to explain intricate concepts. For example, the complexity of the labyrinth of Daedalus resonates with the complexity of the auditory labyrinth. On top of these, being exposed to various literary styles varying from detailed descriptions to terse lyrics, physicians can improve their writing skills in terms of referral letters, patients' records and scientific articles $(3,4)$.

Both literature and medicine originating from nonwritten sources, evolved in a systematic and documented form of practice. The first pieces of epic poetry, Iliad and Odyssey, were written because Peisistratos, the tyrant of Athens ordered so. Homer was lucky to retain the authorship, even though the final version of his poem is believed to have been enriched by the contributions of wandering bards teaching the poem, from generation to generation, by word of mouth. Something similar happened with dramatic poetry. The tragedies of Aeschylus, Sophocles or Shakespeare were actually a compilation of legends. "Our words are the offspring of many people"(5). However, one, who combines synthesizing ability with an extensive knowledge of this background, usually takes the authorship.

Address for correspondence: Christos Tsagkaris, University of Crete, Faculty of Medicine, Heraklion, Greece; Phone: +306980513072, Email: chriss20x@gmail.com

Received: 13.11.2019 Revised:25.12.2020 Accepted: 26.12.2020

Copyright @2021 Heart, Vessels and Transplantation 
In the same period, Medicine evolved from religious centered empiric therapeutics inherited across generations of Asclepian healers - priests to a documented scientific art based on etiology grace to Hippocrates and his disciples (6). Even nowadays, empiric therapies based on herbs and nutritional ingredients such as honey are documented and investigated in the context of phytochemicals and bioactive compounds (7).

Exploring this pattern, we can highlight some notable aspects of the interconnection between medicine and literature. Both literature and medicine need a pool of experience - legends or clinical practice - and a methodology of observation or intervention to translate reality into understanding and understanding into shareable knowledge (8).

In both cases, you have to be eager to work - in the lab, in the clinic and on your desk - and balance inclination with hard work in writing and communicating. Work usually comes with specialization. There are horizontal skills like writing technique or experimental methodology but in both cases, you need a field.

As a doctor, you can be a cardiologist with a research interest in electrophysiology. You understand what is trending in the field, you get to know eminent scholars and fellow researchers and you share a common passion or professional motivation with them. In literature, although you can write both poetry and fiction, eventually you feel more familiar with a genre (poetry, fiction) and a theme (history, fantasy).

Apart from motivation, a supportive environment is necessary. In medicine, this is called funding, research institution or professional affiliation and publishing platforms - either conferences or journals. In literature, you need a basic income - although hardship is a source of inspiration - a publisher, a magazine or newspaper or even a blog where you can present your work, receive criticism and interact with other authors and the audience.

However, there are some substantial differences between Medicine and Literature. Medicine is usually an equivalent of social status. In literature, the appreciation of the public will in most cases come after a long time - or even never. People will name poets and authors that died $50-100$ years ago having most likely endured hunger and confrontation in their lifetime.

Medicine has a more direct impact than literature. It cures or at least relieves. This is the reason why the doctor is the first point of reference when problems, let alone a pandemic, occur. A poet may be the national bard in times of need but in most cases, it takes time to recognize even prominent poets and authors, like Ezra Paount or TS Eliott.

Although both disciplines share a coexistence of vocation, theoretical knowledge and practical skills, medicine is more about ability and less about talent. Students accepted in medical schools obtain the necessary knowledge and skills to practice medicine. Motivation and dedication will make the difference, but one can survive in medicine without them or even substituting them with longing for prestige or income. This is rarely the case in literature. One cannot count on literature as a field providing a decent job, let alone a high salary (9).

Background is also a difference between medicine and literature. It is well known that strong connections willing to support a young professional can skyrocket the likelihood of thriving in medicine. On the other hand, being the son, the daughter or just a close friend of Chekhov cannot upscale your writing in a similar manner. Such connections may open the doors of some publishers, but will neither make your writing appealing to critics and scholars in the long run, nor make a substantial contribution to art, humanities and society (9).

Whichever their similarities or disparities are, medicine is a part of literature. Tracing the whereabouts of literature, we find the sons of Asclepius, Machaon and Podalirius - prominent, capable Achaean physicians - in the Trojan war. In fact, lliad contains detailed accounts of traumatology of the era (10).

However, what we should notice today is that literature is a part of medicine too. The Ward No. 6 of Chekhov illustrates burnout (11). The soliloquy of madness of Macbeth can be read as a psychiatric narrative (12). The Melancholy of Jason Kleander of Cavafy depicts the healing properties of art (13). Reading literature can make physicians more empathetic and observant. Being involved in literary writing, from creative writing classes to blogging can pave new ways for narrative medicine, a field that currently focuses on patients' writing. Literary writing from practicing physicians and researchers can also contribute in science communication demystifying complicated concepts (14). 
In any case, our scientific studies will be outdated in one hundred years from now. However, our literary works may clearly reverberate until then.

Peer-review: Internal Conflict of interest: None to declare Authorship: C.T. and T.I. contributed equally to this piece in terms of acquisition of data, analysis and interpretation of data, drafting of the manuscript, critical revision of the manuscript, statistical analysis, and key administrative, technical, or material support.

CT was responsible for the study concept and design Previous presentation: No previous presentation in a conference/journal Acknowledgement and funding: None to declare

\section{References}

1. Ernest Hemingway's Six-Word Sequels | The New Yorker [Internet]. [cited 2020 Mar 29]. Available from: https://www.newyorker.com/humor/dailyshouts/ernest-hemingways-six-word-sequels

2. Welch TJ, Harrison SL. Teaching medicine through the study of literature: implementing a fourth-year distance learning elective. Acad Med 2016; 91: 360-4.

3. Charon R, Banks JT, Connelly JE, Hawkins AH, Hunter $\mathrm{KM}$, Jones $\mathrm{AH}$, et al. Literature and medicine: contributions to clinical practice. Ann Intern Med 1995; 122: 599-606.

4. Marchalik D. The return to literature - making doctors matter in the new era of medicine. Acad Med 2017; 92: 1665-7.

5. Tria krypha poiemata $=$ Three secret poems / by George Seferis; translated from the Greek by Walter Kaiser. - Version details - Trove [Internet]. [cited 2020 Mar 29]. Available at: URL: https://trove.nla.gov.au/work/5789442?selectedversio $\mathrm{n}=\mathrm{NBD} 31957$

6. Tsagkaris C, Kalachanis K. The Hippocratic account of Mental Health: Humors and Human Temperament.
Ment Heal Glob Challenges J 2020; 3: 33-7. doi:10.32437/mhgcj.v3i1.83

7. Farooq R, Hanif A, Khan A, Arafah A, Rehman MU, Majid S. Molecular mechanisms of phytochemicals from honey in prevention and treatment of cancer. in: therapeutic applications of honey and its phytochemicals. Singapore: Springer Singapore; 2020. p. 61-83. Available at: URL: http://link.springer.com/10.1007/978-981-15-7305-7_4 8. Shapiro J, Nixon LL, Wear SE, Doukas DJ. Medical professionalism: What the study of literature can contribute to the conversation. BioMed Central 2015; 10: Available at: URL: www.ncbi.nlm.nih.gov/pmc/articles/PMC4484639/?

9. A dirty secret: you can only be a writer if you can afford it | Life and style | The Guardian [Internet]. [cited 2020 Dec 26]. Available at: URL: https://www.theguardian.com/us-

news/2020/feb/27/a-dirty-secret-you-can-only-be-a-

writer-if-you-can-afford-it

10.Baltas CS, Balanika AP. Historical Review Achilles and Patroclus: lesser known physicians of Homer's lliad [Internet]. [cited 2020 Mar 29]. Available from: http://www.ismni.org

11. Coulehan MJ. End of the line: depression and burnout in Ward No. 6. 2005.

12. A daggar of the mind": Mental Illness, Masculinity, and Murder in Macbeth | Jeffrey R. Wilson [Internet]. [cited 2020 Mar 29]. Available from: https://wilson.fas.harvard.edu/shakespeare-andcriminology/"a-daggar-of-the-mind"-mental-illnessmasculinity-and-murder-in-macbeth 13. Melancholy of Jason Cleander, Poet in Kommagini, A.D. 595 - Onassis Foundation [Internet]. [cited 2020 Mar 29]. Available from: https://www.onassis.org/initiatives/cavafy-archive/thecanon/melancholy-of-jason-cleander-poet-inkommaginiad-595

14. Holmgren L, Fuks A, Boudreau D, Sparks T, Kreiswirth M. Terminology and praxis: Clarifying the scope of narrative in medicine. Literature and Medicine 2011; 29: 246-73. 


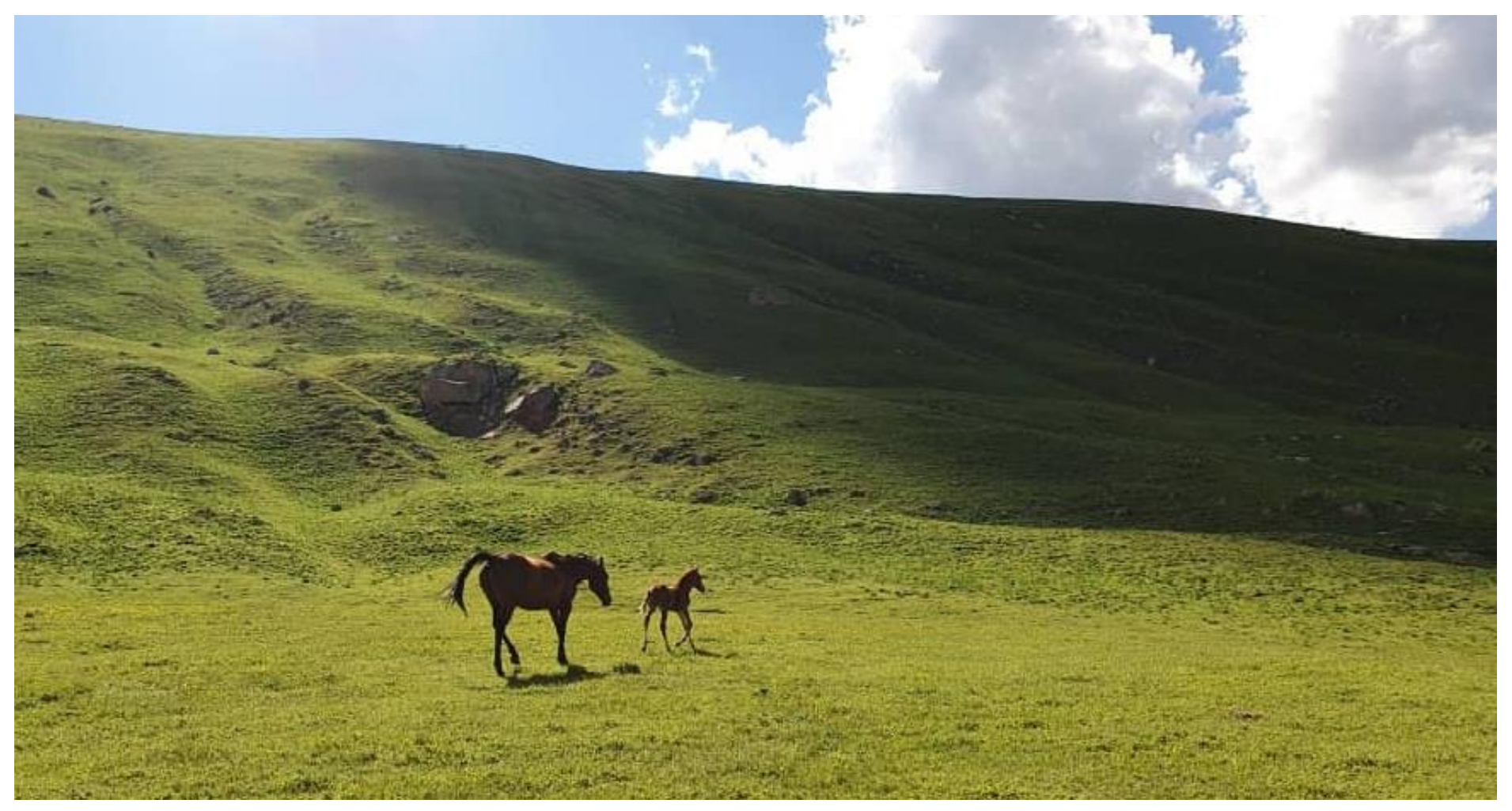

Mare and foal, Chon-Kemin, Kyrgyzstan 2020. Taalaibek Kudaiberdiev, Bishkek, Kyrgyzstan 